\title{
Cognitemes in the Kyrgyz Speech Etiquette and Ways of Their Interpretation in Language
}

\author{
Aigul Abdraeva1, Turusbek Marazykov², Nurila Choibekova3, Dilaram Madaminova4, \\ Aida Zulpukarova4, Zaripa Sagyndykova5, Nurzhamal Ermekbaeva6, Darika Bekkulova7, \\ Zamira Sabiralieva ${ }^{8}$, Zhypargul Abdullaeva ${ }^{9 *}$ (1)
}

\author{
${ }^{1}$ Department of Foreign Languages, Kyrgyz State University named after I. Arabaev, Bishkek, Kyrgyzstan \\ ${ }^{2}$ Department of Kyrgyz Linguistics, J. Balasagyn Kyrgyz National University, Bishkek, Kyrgyzstan \\ ${ }^{3}$ Department of Languages and Intercultural Communication, Kyrgyz State Juridical University, Bishkek, Kyrgyzstan \\ ${ }^{4}$ Department of Philology, Regional Studies, Mathematics and Computer Sciences, Osh State University, Osh, Kyrgyzstan \\ ${ }^{5}$ Department of English Language Teaching Methodic, Osh State University, Osh, Kyrgyzstan \\ ${ }^{6}$ Department of English Phonetics and Grammar, Osh State University, Osh, Kyrgyzstan \\ ${ }^{7}$ Department of American Studies and Translation, Osh State University, Osh, Kyrgyzstan \\ ${ }^{8}$ Department of Russian Language Teaching Methodic, Osh State University, Osh, Kyrgyzstan \\ ${ }^{9}$ Science and Research Department, Osh State University, Osh, Kyrgyzstan \\ Email: ${ }^{\star}$ jypar.science@oshsu.kg
}

How to cite this paper: Abdraeva, A., Marazykov, T., Choibekova, N., Madaminova, D., Zulpukarova, A., Sagyndykova, Z., Ermekbaeva, N., Bekkulova, D., Sabiralieva, Z., \& Abdullaeva, Z. (2021). Cognitemes in the Kyrgyz Speech Etiquette and Ways of their Interpretation in Language. Open Journal of Modern Linguistics, 11, 249-261. https://doi.org/10.4236/ojml.2021.112020

Received: March 30, 2021

Accepted: April 25, 2021

Published: April 28, 2021

Copyright ( 2021 by author(s) and Scientific Research Publishing Inc. This work is licensed under the Creative Commons Attribution International License (CC BY 4.0).

http://creativecommons.org/licenses/by/4.0/ (c) (i) Open Access

\begin{abstract}
The article describes Kyrgyz speech formulas regulating communicating people behavior. Research relevance based on the lack of previous study results about generally accepted prohibitions in the Kyrgyz people speech etiquette, content limit, direction, speakers implementation, presupposing the rules of national communication etiquette and performing important functions in shaping the speech culture of young people. The purpose of this article is to describe cognitive-semantic originality and constructive-syntactic structure of traditional precedent formulas in the Kyrgyz speech ensuring the normal flow of interpersonal communications. After factual material analyses, the main typical requirements for the speech culture distinguished. The most important imperative expressions associating with speech etiquette in the language characterized. Obtained results are necessary for studying the speech culture theory and practice, since they provide general information about requirements in the Kyrgyz speech and verbal communication by contributing to the formation and development of ideas among young people about certain rules for generating speech.
\end{abstract}

\section{Keywords}

Speech Prohibitions, Imperative, Cognitema, Constant, Variation of 
Imperative Expressions, Parasyntagma, Speech Etiquette

\section{Introduction}

The article is devoted to the description of precedent imperative formations of the Kyrgyz language, which limit the content, direction, and implementation of the speaker's speech intentions. All native speakers know these imperatives; they observed in the process of communication and play an important role in the regulation of the speech behavior between participants. During communication, people try to convey with each other certain information and convey the meaning of their words to the interlocutor, prompt something, ask or give advice (Jdetawy \& Hamzah, 2020). Linguistic etiquette refers to the practice in any speech community of organizing linguistic activity (Kasper, 2017). Language forms the means within the language for making linguistic communication in public; modern linguistics focuses more and more on the relationship of such concepts as language and culture (Fowler, 2014; Malyuga et al., 2019).

The precedent imperative formulas relate to the system of paremias and, accordingly, have the properties of the general people, common knowledge, cultural and ethnic content, self-sufficiency of meaning, the presence of a theme and object of reflection, a dark belt structure, situational use, and edifying focus consisting in regulating, positive and improving the atmosphere of communication, as well as the invariance and stability of the total content with the variability and variability of particular values, the paradigmatic-syntagmatic structure of the constituent units, etc. (Zulpukarov et al., 2017). They are widely represented in collections of Kyrgyz proverbs and sayings (Karasaev, 1982; Yudakhin, 2011; Koichumanov, 2012), in studies on ethnography (Akmataliev, 2000; Rysbaev et al., 2016), and the text of works of art (Madmarova, 2017). The cognitive-linguistic essence of imperatives-prohibitions has been the subject of study by several linguists (Zulpukarov et al., 2018; Zulpukarov et al., 2019; Kabylov, 2011; Abdraeva \& Madaminova, 2018a; Abdraeva \& Madaminova, 2018b).

Despite the sufficiently detailed study of the composition and types of Kyrgyz imperatives-prohibitions, both in the linguistic and linguistic-ethnocultural aspects (Zulpukarov et al., 2018; Kabylov, 2011), some aspects of their theory remain outside the linguists' field of vision. For example, the issues of the ratio of constant and particular (variable) meanings in the structure of the rules of the Kyrgyz speech etiquette and the corresponding national-cultural prohibitions, the problems of the paradigmatic-syntagmatic structure of such precedent formulas require comprehension and special description.

Research relevance in this work focused on insufficient study of the generally accepted imperatives-prohibitions in the Kyrgyz people speech, which imply their observance by ethnic group representatives in communication and ensure normal flow of interpersonal communication in society. The purpose of the article is to consider the cognitive-linguistic originality and constructive-syntactic structure of the precedent imperatives in the Kyrgyz speech, which are necessary 
to regulate the society members' speech intention and behavior.

\section{Research Materials and Methods}

The article describes the traditional well-known speech formulas-imperatives of the Kyrgyz people, which determine the content of the speech of participants in communication. In total, we have collected 487 imperatives-prohibitions; only 53 analyzed in the article. The work was performed using descriptive, cognitive, and parasyntagmatic research methods.

In the context of globalization, the Kyrgyz learn and strictly observe the norms of international speech etiquette, and at the same time, they do not forget the precedent speech formulas-imperatives that have been passed down from generation to generation, which determine the content and atmosphere of communication. A common approach in developing the communicational agents based on human speech with specific gestures; speech quality has been measured in many ways, ranging from lexical diversity to conversational fluency (Korcsok et al., 2020; Schwab \& Lew-Williams, 2016). Cognition was subjected to modification through mediation, which is aimed at improving learners' performance (Ebadi \& Asakereh, 2017).

Such imperatives formed as an imperative sentence with a negative verb predicate. In them, predicates are in final position, necessarily contain the affixes of negation, represented in the alloforms -ba/-be/-bo/-be/-pa/-ne/-po/-ne/, and express a positive cognitive meaning. We are cognitive, following E.V. Ivanova, we call the general, constant meaning of the proverb (Ivanova, 2006). It is a unit of memory that exists in the consciousness of an ethnic group and materializes in paremic signs. We represent cognitems of imperative speech formulas in the form of imperative constructions with an invariant meaning, which were realized in specific paremic phrases with negation. For example, the "Tell the Truth" cognition encourages the listener to speak without exaggeration, distortion, lies or bragging. The name given to this cogniteme, according to the Kyrgyz, has a sacred meaning (Ivanova, 2006), and signals that lies and slander can lead to unpleasant and harmful consequences. It was implemented in a number of proverbial expressions. Examples: 1) Karatyp turup kalp aytpa; do not lie when everything is clear anyway. 2) Bilbey turup, bilemin debe/Bilbegendi bilemin dep maktanba; do not say I know without knowing it/do not brag I know when you don't know anything. 3) Korboy turup, kordym debe; do not say I saw without seeing. 4) Soo janyndy ooruu debe, oorup kalasyn; when you are healthy, do not call yourself sick or you will get sick. 5) Bilem bilem dei berbe, uyat bolup kalasyn, bilgenderdi korgondo; do not say I know, I know, you will be ashamed when you see those who know. 6) Jalgan aytpa, jadyna sakta; do not lie, keep in your memory. The key to these imperatives are the imperative predicate verbs with negative suffixes, which urge to speak only the truth.

\section{Results and Discussions}

Ethnic mentality criticizes and hates those who try to lie openly 1), falsify what they knew or did not know, pretend that they know 2), give false testimony 3 ), 
lie to be sick 4), pretend and brag about being educated 5) and generally lie 6). The Kyrgyz demand from the representatives of their nation to evaluate and see all phenomena, events and qualities as they really are. Although only one aphorism clearly indicates the negative consequences of lying, the rest contain such negative reactions "hidden" or explicitly state the negative consequences of lying in a particular situation.

\subsection{Cognition "Speak Appropriately"}

In the Kyrgyz proverbial space, there is the "Speak Appropriate" cognition, which requires speaking following the context, situation, time, and environment, assumes that speech is motivated, truthful, and does not harm anyone. This cognitema is objectified by numerous proverbial expressions: 1) Jatka syr/syrsyndy, Do not tell your secret. 2) Bilbeske soz aytpa; Do not talk to a fool. 3) Kereksiz keptil sozdY syilobo; Do not say unnecessary words. 4) Ooz kesir syilobo; Do not speak arrogantly. 5) Obu zhok sozgo ooz kopturbo; Do not answer to fast words. 6) Teksiz sozgo terikpe, jetesiz sozgo jelikpe; Do not be offended by groundless, do not react to inappropriate words. 7) Kaptaldan kachyryp suylobo; Do not wedge yourself in the conversation. 8) Salamdashpay soz bashtaba; Do not start a conversation without greeting. 9) Uluulardan soz talashpa/talashyp suylobo; Do not compete with adults. 10) Uluulardyn sozun bolbo; Do not interrupt adults' conversation. 11) Uluuga kayasha aytpa; Do not snap at the remarks of your elders. 12) Erten menen jaman suyilobo; Do not speak bad in the morning. 13) Jakshy koshunaga jaramsuz soz aitpa; Do not say bad things to a good neighbor.

In the Kyrgyz speech prohibitions, following sides were distinguished: 1) the speaker (producing speech); 2) the listener (the party to whom the speech addressed); 3) situation, circumstance; 4) spoken word (speech, information). As for the speaker, he does not have a separate nomination and a separate name. It is only implied and presented in the content of the imperative. For example, word aytpa means "don't tell." It is a multifunctional and key member of the offer. The root ait means "say" that contains pronominal meaning "you" and the procedural meaning "to speak", and the addition of negation to the root-na "not" transforms the imperative into a prohibition. In the predicate, the addressee and the speech action prohibited for him given together, simultaneously. The predicate synthesizes information and takes the final position in the phrase.

Speak appropriate cogniteme assumes that speech is motivated, causal, and mutually beneficial for the participants in the communication. It materializes in 24 proverb proverbs. Let us characterize some of them. The constant meaning, "Speak appropriately" is objectified in the formula: cop/secret/syrdy aitpa/ "Don't tell secrets to someone else". This precedent imperative obeys the model $\mathrm{O} 1+\mathrm{O} 2+\mathrm{P}$, where $\mathrm{P}$ is a predicate, $\mathrm{O} 1$ is the first object, $\mathrm{O} 2$ is the second object, which is presented in three equivalent variants (secret/your secret). In the imperative-paremia, there are two object-additions: one in the dative (the reaper to the "alien"), and the other in the nominative (сыр) and accusative (syryny/syryndy) (Figure 1): 


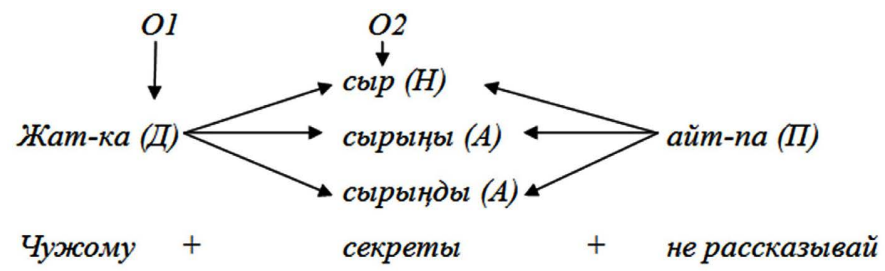

Figure 1. Precedent imperative obeying model $\mathrm{O} 1+\mathrm{O} 2+\mathrm{P}$, where $\mathrm{P}$ is a predicate, $\mathrm{O} 1$ is the first object, $\mathrm{O} 2$ is the second object, which is presented in three equivalent variants (secret/your secret).

Here accepted abbreviations are: $\mathrm{D}$ is dative, $\mathrm{N}$ is nominative, $\mathrm{A}$ is accusative, (A) and (A) are synonymous and represent a truncated and full form of one case. Option $\mathrm{H}$ expresses a more general meaning.

Another expression correlates with this phrase, having a structure similar to it: Bilbes-ke (D) soz (N) ait-pa (P) "Do not talk to a fool". The syntactic composition of the two phrases is the same. They are close and semantically: they emphasize the uselessness of communicating with incomprehensible, narrow-minded people. In both cases, we have a combination of sez aytpa "do not speak, do not speak" (literally "do not say/do not say the word”, sez "word”).

These sentences $(1,2)$ have a constructive and semantic commonality. However, each of them has particular cognition. The specific cognitive-linguistic content of the first is "Don't tell secrets to the enemy". This microcognitema is included in the generalizing cognition "Speak appropriately". The cognitive-linguistic structure of the imperative pair Bilbeske sez aytpa "Don't talk to a fool" (2) is close to the first example. The negation sentence differs from the previous one only in the value of the first component and corresponds to the $\mathrm{O} 1+\mathrm{O} 2+\mathrm{P}$ model. The first word in the phrase contains a negative connotation: bilbes "stupid". At the same time, it contains a negation is "not" (bil is "know, understand, think") and strengthens the content of the formula, allowing it to be used in a wide range of contexts, including such meanings as "does not understand, does not try to understand, mentally retarded, insane, uneducated, ignorant.

This imperative has cognition: "Do not communicate with those who do not understand", which is included in the constant meaning "Speak appropriately" as its particular case. Sometimes O2 may be absent. In this case, the scope of the imperative collapses, the meaning of the word sez "word" shifts to the predicate verb, "condensing" its meaning: Bilbeske sez aitpa $\rightarrow$ Bilbeske aytpa. The three-part syntagma was transformed into a two-part one and received the quality of conciseness and semantic intensity.

The mental-linguistic content of the cogniteme "Speak appropriately" includes the aphorism Kereksiz sezdy/kepti sүılebe "Don't pronounce a word/phrase unnecessarily" (3), where kereksiz sez = kereksiz kep "useless word/phrase". The aphorism expresses the private cognition "Say only what is necessary for a given situation." The idea of this speech formula is the requirement not to deviate from the topic of the conversation, not to deviate from the object of the conversation, to speak only in the direction of the goals, interests, activities of the lis- 
tener and the speaker. At the same time, the speaker is tasked with speaking clearly and unambiguously, taking into account the interests and needs of all participants in communication, striving for brevity and efficiency.

The verbal formula Ooz kesir suylebe "Do not speak without thinking" (4) is also close to this requirement. The idiom ooz kesir (literally "cuts the mouth") has such adverbial meanings as "arrogant/thoughtless/thoughtless/ambitious/boastful/smug", which determine the characteristics of the speech produced. Such speech is prohibited by folk etiquette. In the Kyrgyz linguo-ethnic culture, there are paremic sayings: Oinop suyloson da, oylop suylo "Even joking, speak after thinking", Oilonboy suylegen ontoboy ooruga kabylat "Whoever speaks thoughtlessly speak, he will get sick asymptomatically", Oyloboi suylegen adam jurttun azaby means does not think grief of the people) and others, which, corresponding to this cognition, convey the value attitude of our people to the word, to its relevance and deliberation. The word ooz "mouth" designates not only one of the organs of speech, but also participates in the transmission of the meanings "speech, word, utterance; speak, say", idioms oozuna kara "speak after thinking (follow the speech)" (literally "look at your mouth"), achuk ooz ayal "a woman who speaks openly, without embarrassment, without worshiping, without hiding anything" (literally "a woman with an open mouth"), etc. Thus, the essence of the prohibition Ooz kesir suylebe "Do not speak without thinking" can be defined as "Think before speaking".

The considered precedent imperative-negation is somewhat different in structure and meaning from the aphorism Obu jok sozgo ooz kopturbo "Don't answer shameless words arrogantly (don't answer thoughtless words)" (5), consisting of five words. The root is related, is not used independently, and is found only in the idiom of footwear "obscene, shameless, thoughtless" (literally about "conscience, shame" and jok "no, absent"). This expression is also a taboo phrase. We see that in the first part of the speech formula of the trainer sez the meaning is conveyed "shameless/awkward/awkward/rude word", and in the second part of the ooz kepturbe the meaning is "do not speak arrogantly, arrogantly, boastfully". The imperative allows transformation: its second part is sometimes replaced by negative tekeberlenbe predicates "do not be arrogant, do not answer arrogantly, do not adequately answer", terikpe "take it calmly, do not answer accordingly", which do not contradict the cognition "Answer inconvenient words correctly".

\subsection{Representatives of Cognitheme "Speak Appropriately"}

Another verbal formula (6), which differs significantly from the previous ones in its structure, is suitable for the representations of the "Speak pertinently/to the place" cognition. Cognitema objectified twice here because this aphorism consists of two parallel sentences. Each of the simple sentences materializes cognition:

Tek-siz sez-ge terik-pe "Do not be offended by groundless words", 
Zhete-siz sez-ge zhelik-pe "Do not react to inappropriate words."

In parts of the proverb, we see complete parallelism: a negative predicate corresponds to a negative predicate, an object in a dative an object in a dative, a negative definition with negation. At the same time, in two lines of a proverbial phrase, the coincidence of root and affixed morphemes, the same types of word connections were found. The expressiveness of a proverb and in addition, repetitions, rhyme and rhythm in parts of the phrase were developed.

Their first part is synonymous with the first part of the previous (5) aphorism: "to shameless words (to thoughtless words)" (5) = texiz sezge "to groundless words" (6) = zhetesiz sezge "to inappropriate words" (6). Referring to the last two phrases, you can see that the root tek is a generalized nominee of the meanings "origin, basis, argument, reason", and the root zhety, the meanings "origin, ancestors, seven generations on the father's side (zhete = zheti "seven"), the foundation". Each lexeme in a proverb receives a generalizing property: the nature of the proverb itself imposes a multivalued function on its components.

So, in two examples $(5,6)$, contextual synonyms of training = texis $=$ zhetesiz sez are in the dative with the affix- $\boldsymbol{r \theta}$ and convey the meaning "inconvenient/unreasonable/unmotivated/groundless/awkward/opinion/thought”. Therefore, the object in the dative expresses, in fact, the same meaning in all three sentences. However, the compared predicates of proverbial structures are different. The predicate of the first sentence means ooz keptyrbe means "do not speak arrogantly" (literally, "do not blow up your mouth"), the predicate of the second sentence terikpe means "do not be offended, do not respond with resentment, do not waste your honor, words and time", the predicate of the third sentence is jirikpe "do not react, do not be upset." In all three sentences, the addressee-subject enclosed in the semantic structure of the predicate, is not verbally expressed and materialized in the form of an imperative. The subject is a potential executor of the action. It can be singular or plural. The subject of the execution of actions in the proverb is a generalized person, and in each situation of the application of the proverb, a specific person, specific people become him. In real conditions, the imperative acquires a specific speaker and listener in the roles of producer and recipient of the communication.

The previous proverb (5) suggests a situation when the addressee-subject offends and humiliates another with his speech, aggressiveness, and foul language. His words are rude and unethical, he speaks harshly and arrogantly. It contains advice: "You do not have to respond to rudeness with rudeness/You do not have to respond to arrogance with arrogance." The proverb calls on the listeners to be courteous. A call to politeness, tolerance, and understanding is also contained in the paired dictum (6).

\section{3. "Do Not Wedge Yourself in the Conversation"}

In the culture of speech, there is another formula of etiquette: Kaptaldan kachyryp syilybe "Do not wedge yourself in the conversation" (7). It contains the re- 
quirement not to interfere with the conversation, not to interfere with it, to treat the interlocutors with respect, but only if necessary, you can turn on politely, taking into account the situation. There should be no humiliation, insult, or intimidation when entering a conversation.

It is important to show respect not only to those with whom you are already talking but also to those with whom you are just about to talk. There is a rule: Salamdashpay sez bashtaba "Before you start talking, you need to say hello" (8). The greeting evokes positive emotions in the addressee, a reaction to the greeting, and an attempt to honor the person. In this case, any problem can be solved positively and consistently.

When the mood is good in the morning, a person is happy all day, works productively, the way he would like, and, naturally, his attitude towards others is positive and benevolent. If he is frustrated, upset, or worried, his work will be ineffective and negatively affect those around him and those close to him. There is an ethnic demand that predicts such a situation: Erte menen zhaman suylebe "Do not speak badly in the morning" (9).

A person who is guided by this rule never offends does not offend his loved ones in the morning and, on the contrary, positively attunes them, patiently and calmly solves all problems. There is no need to remember and discuss the past. Thus, the Kyrgyz always encourage tolerance and benevolence. The cognitive theme of this proverb is "Don't spoil the mood of others in the morning." In the speech formula, the object is implicitly conveyed in the semantics of the predicate suylebe "do not say".

\subsection{The Proverb "Do Not Say a Bad Word to a Good Neighbor"}

The proverb Zhakyn koshunaga zharamsyz sez aitpa "Do not say a bad word to a good neighbor" (10) has the structure (Figure 2):

Abbreviations: I-an imperative dictum, $\mathrm{P}-\mathrm{a}$ predicate with negation, O1-an object in the nominative, A1-an attributive word with a negation-from "without", O2 - an object in a dative, consisting of a stem, an affix "your", and the affix dativa-a, A2 is an attributive word.

The proverb-sentence consists of five members. The keyword in it is "don't tell". It obeys the object (O1) сөз in the nominative with the definition (A1) zharam-syz "bad, unacceptable", as well as the object (O2) koshunaga "to your neighbor" (-ң “your") in the dative with the definition (A2) zhakshy "good".

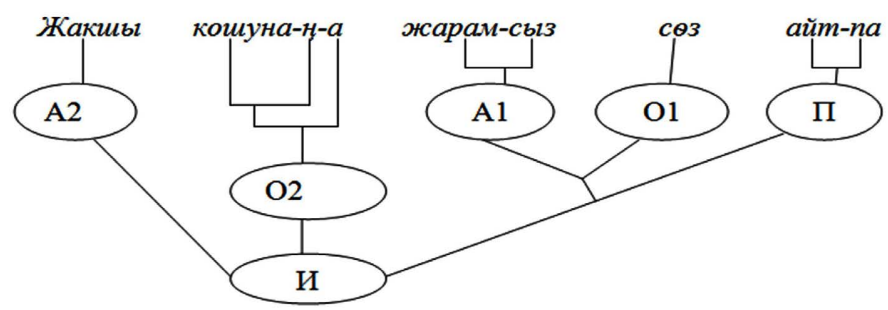

Figure 2. Proverb structure "Zhakyn koshunaga zharamsyz soz aitpa". 
The proverb under consideration allows for a wide variation: the first attributive-objective phrase zhakyn koshunana "close neighbor" can be replaced by synonyms zhakshy koshunaga "good neighbor", ynak koshunaga "friendly neighbor", ishengen koshunana "tested neighbor", etc. (where -ң "your", is a sign of the dative case), the second attributive-object phrase is zharamsyz soz "unpleasant word"—synonymous with obzhok soz "shameless (stupid) word", zhaman sz "bad word", odono sez "rude (offensive) word", kesir sez "dismissive word”, odono sez "rude (offensive) word”, kesir sez "dismissive word”, kakshyk sez "stinging word", etc., and the imperative predicate aytpa "do not say" (ayt "say") synomim suylebe "Do not say" (suyle "say"). In this case, the imperative form can be transformed into the declarative form of the third person verb: aytpa $\rightarrow$ aytpayt, sүılebe $\rightarrow$ syllebeit, which will certainly eliminate the personal possessive affix of the 2nd person- "your", depriving the object of the attribute of belonging to the 2 nd person. Such a transformation of the phrase does not affect the meaning: in all transformations, the positive cognitive content "A good neighbor must be treated kindly" is preserved. The ratio of transforms of the original imperative can be represented as a diagram (Figure 3):

Variants of the proverb are quite fully registered in collections of folk sayings (Koichumanov, 2012). The respondents also confirmed the legitimacy of the existence of these variants in the speech of the speakers of the Kyrgyz language, noting at the same time the commonness and prevalence of two variants: Zhakyn koshunaga jaman sez aitpa; Zhakshy koshunaga zhaman sez aitpayt.

In this case, we can talk about the paradigmatic-syntagmatic structure of the proverb variants, opposing the widespread opinion about the rigid stability and cliché of the proverbial units of the language. In our examples, one of the object names (s ( $\mathrm{z}$ "word") turned out to be stable, the names of another object (koshunaga "to your neighbor", koshunaga to "neighbor") and the predicate (aytpa/aytpayt, suylebe/suylebeit "do not say/do not speak") received two forms each, the largest number of transforms are allowed by the attributive terms of phrases.
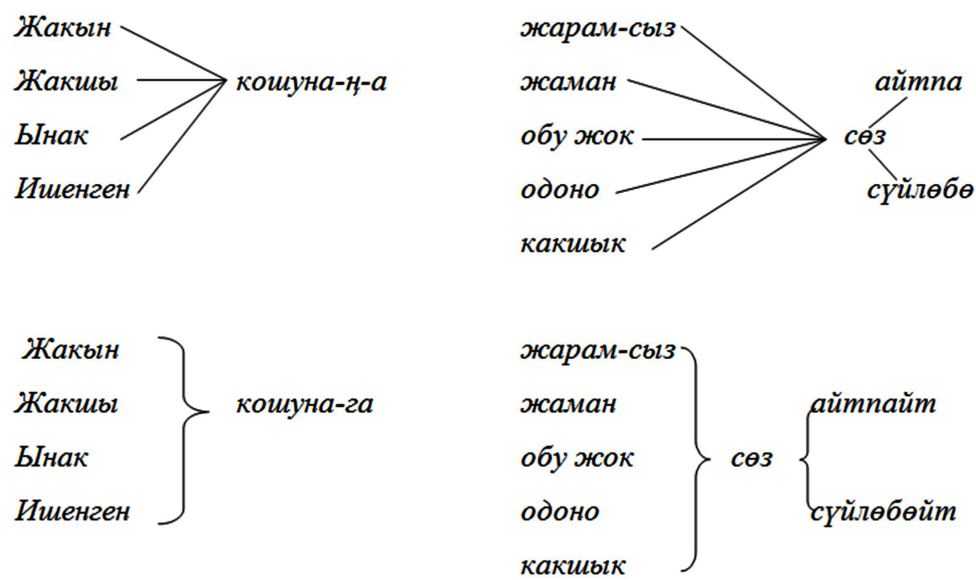

Figure 3. Transformations in proverb "Zhakyn koshunaga zharamsyz soz aitpa." 


\subsection{Cognithema "Keep the Given Word"}

In the Kyrgyz linguistic culture, there are imperative formations related to the cogniteme "Keep the given word": 1) Birøe menen deshpe, deshsen kelzhireshpe "Do not negotiate with anyone, after agreeing do not refuse." 2) Aytpa, aitkandan kiyin kaitpa "Do not promise, if you promise, do it." 3) Aytkanyndan kaitpa, aldyndan zhoo chyksa da kaira tartpa "Do not refuse this word, do not retreat, even if the enemy is in front of you." four. Ubadadan kaitpa "Don't give up on the promise." There are only four examples of this value registered in our file cabinet. The mentality of the ethnos requires that before promising something to another, each of its representatives think about the problem, consult with relatives and knowledgeable people, weigh the pros and cons, foresee the expected results, and only then give their word. The people condemn people when they do not fulfill their promises. Therefore, it was considered a negative phenomenon to agree and then quarrel (1), accept the task and not fulfill it $(2,3)$, refuse a promise (4). Resilience in keeping promises is a positive human quality that is a sign of thoughtful action, weighing one's promises, and responding to the "Keep your word" cognition. All these representations of cognition can be defined as socially significant rules necessary to regulate the relationship between people and their acceptance of feasible and thoughtful tasks.

\subsection{Cognitema "Speak Carefully"}

In the mental-linguistic thinking of the Kirghiz there is a cognition "Speak carefully", which in their speech etiquette is represented in several imperative expressions. These imperatives can be divided into two groups, with their own small cognitions.

A) "Speak carefully with special people": 1) Sarał menen maekteshpe "Do not communicate with the stingy." 2) Karyptyn kargyshyn alba "Beware of the curse of the dispossessed". 3) Kichinege chonsunba "Do not put on airs in front of the younger (weak)." 4) Karyga katuu aytpa "Don't be rude to an elderly man." 5) Buzuku menen mudashpa "Do not share with the troublemaker (your sorrows and joys)/Do not confess with the troublemaker." 6) Zhamandyn atasyn suraba "Don't ask a bad father about his father/Don't ask a fool about his roots." 7) Dushmanga syrygy aitpa "Do not tell your secret to the enemy/Do not reveal your soul to the enemy."

B) "Speak deliberately": 1) Sezge seykenbe, kepke keptelbe "Do not speak taunts, do not squeeze into the conversation/do not interrupt the speaker." 2) Kargyshty bilbesen, bireeden yirenbe "Not knowing curses, do not learn from others." 3) Oyuna kelgen sozdy aitpa "Do not say the word that comes to mind/Do not say what came to mind first." 4) Sozge seltuk, kepke kemtik bolup zhurbe "Do not blush from a shameful and degrading word."

C) All proverbs contain a prohibition, which is conveyed by verbal predicates of phrases in the imperative form with final negative affixes:

-ba/-be/-bo/-be/-pa/-ne/-po/-ne/"not". In many proverbs, there is a consonance 
of words. Sound harmony is especially noticeable in examples B-1 and B-4. In imperative B-1, there are two homogeneous, one-type sentences, each of which has five vowel sounds $\theta$, e in its structure, ensuring the euphony of phrases. In example B-4, the combinations Sezge seltuk, kepke kemtik form a kind of harmony of parallelism and consonance of vowels and partially consonants:

S- - -z-g-e s- $-1-\mathrm{l}-\mathrm{t}-\mathrm{Y}-\mathrm{k}$,

K-e-p-k-e k-e-m-t-i-k

As for the structure and semantics of imperatives-prohibitions, the examples of the two groups (A, B) show some differences. The cognitive-semantic structure of the first group (A) includes two paradigms: 1) the names of people with special qualities denoted by substantivized adjectives: saray "stingy", karyp "disadvantaged, beggar", kichine "younger, weak", punishment "old, elderly", Bouzuku "troublemaker, troublemaker", zhaman "bad, bad, unworthy", dushman "enemy"; 2) imperatives requiring the addressee to speak carefully or not to speak at all: maekteshpe "do not communicate", kargyshyn alba "do not accept curses/beware of curses", choңsunba "don't be important/don't show arrogance”, katuu aitpa "don't be rude", muңdashpa "do not share your sorrows", suraba "do not ask."

The connection of these two paradigms creates a separate paradigmo-syntagmatic form and requires people to comply with certain norms of speech behavior - not to talk and not to contact the stingy (1), not to offend the disadvantaged, the poor and the poor (2), not to humiliate the young and the weak (3), speak rudely with the elderly (4), do not keep people with inflammatory nature close to you (5), be interested in the origin of vicious people (6) and reveal their secret to the enemy (7).

The imperatives of the second group (B) have a general meaning: "Speak deliberately", which is objectified in four imperative proverbial units. They contain requirements not to speak barbs and interrupt the conversation (1), not to learn to use curses in speech (2), to speak thoughtfully (3) and not to use abusive and obscene words (4).

These imperatives contain several tips that are especially important for young people. Their implementation will make a significant contribution to the regulation of interpersonal relations and people's behavior in society.

Several imperatives of the Kyrgyz speech etiquette are grouped around the cogniteme "Swearing is a sin". This is a generalized judgment covering many verbal prohibitive formulas. In the Kyrgyz lexicon, the words segyY "scold", segunuu "scold, swear" and their derivatives form a separate group and are considered nominees for rude statements. It is common among men to use swear words in speech. Women's cargo "abuse" is interpreted as a curse (Yudakhin, 1985). The curse is also characteristic of the speech of men.

Examples related to this cognition: 1) Eldi sekpe, yryskysyn tekpe "Do not abuse the people; do not deprive them of their well-being." 2) Kyzdy sekpe, urba/Kyz balany sekpe "Do not scold or beat the girl/do not scold the girl." 3) Shamaldy sekpe/Ottu teppa, shamaldy sekpe "Do not scold the wind/Do not 
kick the fire with your foot, do not scold the wind." 4) Zhamgyrdi urushpa "Don't scold the rain". 5) Ay, kүnge akaarat keltirbe "Do not insult the moon and the sun."

These prohibition formulas require a careful attitude towards certain objects of reality, emphasize the holiness and greatness of the people, the curse against them, in the opinion of the ethnos and deprives the people of the blessings of life (1). They note the tenderness, sensitivity, vulnerability of a girl/little girl (2), the groundlessness of the curse of natural phenomena and the need for a careful attitude towards them $(3,4)$, because only thanks to them there is their life on earth. In fact, great natural phenomena (sun, moon, wind and rain) do not obey the will of man and do not change at their will. Their existence is determined by the laws of nature, the laws of the universe. Therefore, the Kyrgyz mentality requires people to respect natural processes.

\section{Conclusion}

Research materials allow us to draw some conclusions:

1) Formulas of speech etiquette are created and accepted by the people, are well known, and regulate the behavior of people in society.

2) The imperatives of etiquette formed mainly in the form of negative imperative sentences. Their predicates necessarily contain negation affixes.

3) Kyrgyz imperatives-prohibitions, although based on negative predicates, express positive content and represent such cognitive patterns and constant meanings that are important for interpersonal communication and sustainable maintenance of relationships between people in society.

4) The rules of speech etiquette, assigned to the imperative formations of the language, limit the content, direction, and implementation of the speech intentions and abilities of the speech producer.

5) Imperative formulas of speech etiquette refer to paremias and have all their properties nationwide, national and cultural content, relative stability, self sufficiency of meaning, dark-belt structure, situational use and variation, edifying orientation, the presence of invariant (cognitive) content, etc.

The practical implication in this study is assimilation of speech etiquette formulas necessary to regulate the behavior of an individual in society, to positively maintain the participants' behavior in communication and teach young people the traditional norms of communication.

\section{Conflicts of Interest}

The authors declare no conflicts of interest regarding the publication of this paper.

\section{References}

Abdraeva, A. T., \& Madaminova, D. B. (2018a). Kyrgyz Linguo-Ethnocultural Prohibitions from the Point of View of Turkish and English Mentality. Modern Trends in the Development of Science and Technology. Periodic Scientific Collection. Belgorod, Part 
I, 6-11.

Abdraeva, A. T., \& Madaminova, D. B. (2018b). Linguo-Ethno-Mental Taboos of the Kyrgyz People Associated with Food and Animals. New Technologies in Social Sciences, Humanities, and Education: Current State, Problems, Development Prospects. Periodic Scientific Collection. Belgorod, Part I. 11-18.

Akmataliev, A. S. (2000). Ageless Kyrgyz values (p. 348). Bishkek.

Ebadi, S., \& Asakereh, A. (2017). Developing EFL Learners' Speaking Skills through Dynamic Assessment: A Case of a Beginner and an Advanced Learner. Cogent Education, 4, Article ID: 1419796. https://doi.org/10.1080/2331186X.2017.1419796

Fowler, C. A. (2014). Talking as Doing: Language Forms and Public Language. New Ideas in Psychology, 32, 1-16. https://doi.org/10.1016/j.newideapsych.2013.03.007

Ivanova, E. V. (2006). Peace in English and Russian Proverbs (p. 278). St. Petersburg.

Jdetawy, L. F., \& Hamzah, M. H. (2020). Linguistic Etiquette: A Review from a Pragmatic Perspective. Technium Social Sciences Journal, 14, 695-717.

Kabylov, T. B. (2011). The Linguistic Essence of the Imperative (p. 22). Thesis, Bishkek.

Karasaev, H. (1982). Folk Sayings (p. 368). Frunze.

Kasper, G. (2017). Linguistic Etiquette. In F. Coulmas (Ed.), The Handbook of Sociolinguistics (pp. 374-385). Hoboken, NJ: John Wiley \& Sons. https://doi.org/10.1002/9781405166256.ch23

Koichumanov, J. (2012). Proverbs, Sayings, Catchphrases, Wise Thoughts (p. 540). Bishkek: Biyiktik Plus.

Korcsok, B., Faragó, T., Ferdinandy, B., Miklósi, Á., Korondi, P., \& Gácsi, M. (2020). Artificial Sounds Following Biological Rules: A Novel Approach for Non-Verbal Communication in HRI. Scientific Reports, 10, Article No. 7080. https://doi.org/10.1038/s41598-020-63504-8

Madmarova, G. A. (2017). Intercultural Concepts in the Text of a Work of Art (p. 392). Bishkek.

Malyuga, E., Maksimova, D., \& Ivanova, M. (2019). Cognitive and Discoursive Features of Speech Etiquette in Corporate Communication. International Journal of English Linguistics, 9, 310-318. https://doi.org/10.5539/ijel.v9n3p310

Rysbaev, S., Ibragimova, K., \& Asrankulova, B. (2016). Sacred Words of the Elders. Essays on Kyrgyz ethnography (p. 256). Bishkek.

Schwab, J. F., \& Lew-Williams, C. (2016). Language Learning, Socioeconomic Status, and Child-Directed Speech. WIREs Cognitive Science, 7, 264-275.

https://doi.org/10.1002/wcs.1393

Yudakhin, K. K. (1985). Kyrgyz-Russian Dictionary (p. 474). Book II, Frunze.

Yudakhin, K. K. (2011). Kyrgyz Proverbs and Sayings (p. 199). Bishkek: Academy of Science Collection.

Zulpukarov, K. Z., Abdulatov, A. A., Kamardinova, U. N., Kozhoeva, G. Zh., Ergeshova, S. B., \& Eshmanova, S. K. (2018). Actual Problems of Linguopoetics and Linguoparemi$\operatorname{olog} y$ (p. 828). Bishkek.

Zulpukarov, K. Z., Atakulova M. A., Kalmurzaeva, A. A., Ayylchieva, D. T., \& Dzhusupova, A. A. (2017). Invariance in the Pronominal and Proverbial Language Paradigms (p. 28). Bishkek.

Zulpukarov, K. Z., Muradymova, E. N., Ormokeeva, R. K., Bolotakunova, G. Zh., \& Amiraliev, S. M. (2019). Linguistic Anthropocentrism: Problems, Searches and Solutions (p. 743). Bishkek. 